\title{
Study of High Temperature Crack Initiation and Growth in Light Capturing Ribbon (LCR) PV Module Interconnection
}

\author{
Alireza Eslami Majd ${ }^{\mathrm{a} \star 1}$ and Nduka Nnamdi Ekere ${ }^{\mathrm{a}}$ \\ ${ }^{a}$ School of Engineering, Faculty of Science and Engineering, University of Wolverhampton, UK
}

${ }^{\star}$ Corresponding author E-mail addresses: a.e.majd@wlv.ac.uk

\begin{abstract}
The ribbon interconnection between solar cells (used for collecting current from solar cells) is a key PV module component and it highly affects the reliability of PV module as interconnection failure can lead to PV module performance. Light Capturing Ribbon (LCR) is a new type of interconnection to increase the efficiency of PV modules by reflecting the incident sun rays from the interconnection ribbon to the cell surface. This paper studies a comparison of the crack initiation and growth in the PV module interconnection due to the high-temperature manufacturing process between Light Capturing Ribbon (LCR) and Conventional Ribbon (CR). Extended Finite Element Method (XFEM) in ABAQUS software is employed to find the Crack Initiation Temperatures (CIT) and the Crack Growth Rate (CGR) for different configurations of PV module interconnection designs. The optimum solder, silver, and copper thickness for LCR interconnection are recognized as $20 \mu \mathrm{m}, 40 \mu \mathrm{m}$, and $125-187.5 \mu \mathrm{m}$, respectively, where this configuration experiences smaller cracks in the solder joint material rather than $\mathrm{CR}$ interconnection with the same cross-section area.
\end{abstract}

Keyword

PV Module Interconnection, Light Capturing Ribbon, Crack Initiation and Growth, Thermal stress, XFEM

\section{INTRODUCTION}

There are many efforts to drop the cost of PV modules down and to warrant higher lifetime of the modules; then it can be expected that PV modules will become the cheapest source of electricity over the next two decades. However, there is a challenge to improve the PV module performance by re-designing the PV module Interconnection. In a PV module, a common crystalline silicon cell only produces a voltage of $0.5 \mathrm{~V}$ which is 
very weak to feed energy into the electrical power networks ${ }^{[1]}$. To produce higher voltages, the front-to-back cell interconnection technique is being mostly used for the series-parallel (SP) connection of the silicon cells due to its simplicity. However, this technique suffers a high partial shading due to reflection of the incident rays from the surface of the used interconnection ribbons and it is reported that the standard interconnection ribbons occupy about $\% 2.3$ of the cell's surface ${ }^{[2,3]}$. The front-to-back cell interconnection technique uses interconnection ribbons to connect the individual cells and to deliver the generated current from each cell to the final output terminals. Hence, the interconnection ribbon is one of the main parts in PV modules as their failure can negatively affect both the performance and reliability of PV modules. Furthermore, using interconnection ribbons for the series connection of the cells increases the series resistance. To decrease the series resistance between cells, using more or wider interconnection ribbons can be a practical solution, but this causes more shading effects and more reduction in the short circuit current. It should be mentioned that as power loss goes as the square of the current, there is a higher decrease in the power output ${ }^{[4]}$. Multi-Busbar (MBB) and Light Capturing Ribbon (LCR) interconnections are novel designs to decrease the shading effect. MBB design uses small round wires to reflect the incident light from the ribbon surface onto the wafer surface and it makes less losing the received energy in comparison with conventional ribbon (CR) interconnection ${ }^{[5,6]}$. However, MBB connector may suffer manufacturing errors associated with the non-homogeneity of solder coating around the $\mathrm{Cu}$-wire which leads to weaker solder joints ${ }^{[7]}$ as up to $21 \%$ reduction in the cracking temperature of the solder joint was found ${ }^{[8]}$.

Light-Capturing/ Harvesting Ribbon (LCR/ LHR) concepts replacing standard interconnection ribbons in solar cell tabbing. LCR uses a grooved surface to reflect more light back onto the cell surface (see Figure 1). It is found that using LCR improves the photocurrent recapture ratio of ribbon from $6 \%$ to about $50 \%$; and this results in an increase of the module short circuit current and the power gain by $1.3 \%$ and $1.7 \%$, respectively ${ }^{[9]}$.

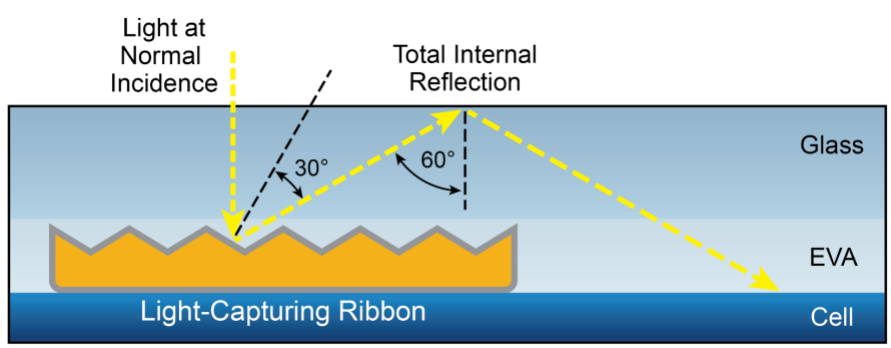

Figure 1 Schematic view of optical path and reflecting light back onto the cell for a structured LightCapturing Ribbon ${ }^{[10]}$

Reliability of the PV module interconnection is one of the key parameters of the reliability of the whole PV module as it is reported that more than $40 \%$ of all failure in crystalline silicon solar cells is relevant to failure of the interconnection ${ }^{[11]}$. For any design of the interconnection ribbon, it is necessary to study interconnection failure modes to ensure that the design is enough reliable. The main failure mode of PV module interconnection is failure of solder joint material that is caused by high accumulated strain energy due to the coefficient of thermal expansion (CTE) mismatch between interconnection materials. The induced strain energy in solder joint leads to micro-crack nucleation at the interface between the solder and its bonding pads that contains the brittle Intermetallic compounds (IMCs) layer. The IMC layer forms whenever two different metals are soldered together. Indeed, diffusion of copper ( $\mathrm{Cu}$ ) and tin ( $\mathrm{Sn}$ ) elements in the soldering process causes formation of the IMC layers.

The failure of solder joint becomes more important when the solar cell experiences high temperatures, particularly during vacuum lamination in the manufacturing process which the cells need to be heated up to $150^{\circ} \mathrm{C}$, to develop a network of ethylene-vinyl-acetate (EVA).

In this study, the crack initiation temperature (CIT) and the crack growth rate (CGR) in the IMC layers of 
lead-free solder joint materials at high temperatures of the manufacturing process are investigated. The CIT and the CGR are considered as main parameters to evaluate the crack length at high temperatures and this helps to estimate the reliability of the PV modules. The CIT and the CGR associated in the solder joint of LCR are found and they are compared to the relevant parameters of $\mathrm{CR}$ interconnection found in the previous work ${ }^{[12]}$.

\section{FINITE ELEMENT SIMULATION}

To determine the CIT and the CGR in the solder joints of PV module interconnection, Extended Finite Element Method (XFEM) in ABAQUS software is used. XFEM is developed as a computational feature of ABAQUS and; unlike ordinary FEM, XFEM does not required defining the crack geometry or re-meshing the part beforehand. XFEM extends conventional finite element method and allows local enrichment discontinuous functions to be combined with the numerical approximation ${ }^{[13]}$. To investigate the damage initiation, the maximum nominal stress of Shear and Tensile components are considered as the controlling parameters of the tractionseparation laws. Also, the initiated damage is progressed according to the Fracture Energy formulations based on the parameters of Fracture Toughness and Elastic Modulus ${ }^{[14]}$. The applied FE technique to simulate the crack initiation and growth is validated with the experimental results from a tension ${ }^{[15]}$; and the results showed a very good agreement in Force-Displacement curve.

2D symmetrical geometries of the interconnection ribbon with using the 3-and 4-node plane-strain elements are applied in ABAQUS 2019. A view of FEM simulation of LCR interconnection on the crystalline silicon cell is shown in Figure 2. Figure 2 also depicts the material arrangement and the view of structural grooves of the LCR interconnection. The IMC layers are modelled as the boundary layers of the solder joint materials. A very fine meshing element ( $1 \mu \mathrm{m}$ elements) is applied for the IMC layer. Linear Elastic behaviour is considered to investigate the fracture mechanics of the IMC layers due to their brittle material behaviour. The tensile Strength, the shear strength and the fracture toughness of the IMC layer are considered as $55 \mathrm{MPa}, 20 \mathrm{MPa}{ }^{[16]}$ and $1.4 \mathrm{MPa}$. $\mathrm{m} 0.5^{[17]}$, respectively. The Energy release rate, $\mathrm{G}$, for the plane strain state is calculated according to eq.1; where; $\mathrm{K}_{\mathrm{I}}, \mathrm{v}$ and $\mathrm{E}$ are fracture toughness, Poisson's ratio and Young's modulus, respectively ${ }^{[13,14]}$.

$$
\frac{K_{I}^{2} *\left(1-v^{2}\right)}{E}
$$

In this study, the isotropic mechanical properties for the PV module materials are considered (see Table 1). To consider more realistic behaviour of the materials, the CTE of main materials, the Young's Modulus of the IMC layer and plastic behaviour of the solder joint are assumed temperature dependent (see Table 2). The isothermal temperature by increments of $15^{\circ} \mathrm{C} / \mathrm{min}$ is applied to the whole model.

Table 1 Material properties of the PV module materials

\begin{tabular}{|c|c|c|c|c|c|c|c|}
\hline Parameter (unit) & IMC & Solder Joint & Silver ${ }^{[18]}$ & Copper ${ }^{[19]}$ & $\mathrm{EVA}^{[20]}$ & Silicon $^{[21]}$ & Glass $^{[22]}$ \\
\hline Young's modulus (GPa) & 110 & $\begin{array}{c}\text { See } \\
\text { Table } 2 \\
\end{array}$ & 69 & 121 & 11 & 130 & 73.0 \\
\hline Poisson's Ratio (-) & 0.3 & 0.35 & 0.365 & 0.34 & 0.499 & 0.28 & 0.235 \\
\hline Yield Stress $(\mathrm{MPa})$ & - & - & 43 & 121 & 12 & 170 & - \\
\hline $\begin{array}{l}\text { Thermal Expansion } \\
\text { Coefficient (ppm/k) }\end{array}$ & $\begin{array}{c}\text { See } \\
\text { Table 2 }\end{array}$ & $\begin{array}{c}\text { See } \\
\text { Table 2 }\end{array}$ & $\begin{array}{c}\text { See } \\
\text { Table 2 }\end{array}$ & $\begin{array}{c}\text { See } \\
\text { Table 2 }\end{array}$ & 270 & $\begin{array}{c}\text { See } \\
\text { Table 2 }\end{array}$ & 8.0 \\
\hline $\begin{array}{l}\text { Plastic Stress-Strain } \\
\text { Curve (MPa) }\end{array}$ & - & $\begin{array}{c}\text { See } \\
\text { Table } 2\end{array}$ & $\begin{array}{l}43 \text { at } 0.001 \\
120 \text { at } 0.04\end{array}$ & $\begin{array}{l}121 \text { at } 0.001 \\
186 \text { at } 0.004 \\
217 \text { at } 0.01 \\
234 \text { at } 0.02 \\
248 \text { at } 0.04\end{array}$ & - & - & - \\
\hline
\end{tabular}


Table 2 temperature dependency of mechanical properties of the PV module materials

\begin{tabular}{|c|c|c|c|c|c|c|c|}
\hline Temp. $\left({ }^{0} \mathrm{C}\right)$ & $\begin{array}{c}\text { CTE for Copper } \\
(\mathrm{ppm} / \mathrm{k})^{[23]}\end{array}$ & $\begin{array}{c}\text { CTE for Silicon } \\
(\mathrm{ppm} / \mathrm{k})^{[22]} \\
(\text { Interpolated })\end{array}$ & $\begin{array}{c}\text { CTE for Silver } \\
(\mathrm{ppm} / \mathrm{k})^{[23]} \\
(\text { Interpolated })\end{array}$ & $\begin{array}{c}\text { CTE for IMC } \\
(\mathrm{ppm} / \mathrm{k})^{[24]} \\
(\text { Interpolated })\end{array}$ & $\begin{array}{c}\text { CTE for Solder } \\
(\mathrm{ppm} / \mathrm{k})^{[25]}\end{array}$ & $\begin{array}{c}\text { Solder Young's } \\
\text { Modulus }^{\text {Plastic Stress for }} \\
(\mathrm{GPa})^{[25]}\end{array}$ & $\begin{array}{c}\text { Solder }(\mathrm{MPa})^{[26]} \\
(\text { Interpolated })\end{array}$ \\
\hline 0 & 16.22 & 2.35 & 18.67 & 17.7 & 21.3 & 49 & 71,145 \\
\hline 30 & 16.60 & 2.63 & 18.98 & 18 & 21.81 & 46.9 & 52,131 \\
\hline 60 & 16.91 & 2.87 & 19.20 & 18.3 & 22.32 & 44.8 & 16,110 \\
\hline 120 & 17.22 & 3.04 & 19.42 & 18.6 & 22.83 & 42.7 & - \\
\hline 150 & 17.53 & 3.20 & 19.65 & 19 & 23.34 & 40.6 & - \\
\hline
\end{tabular}

In this study, the thickness of IMC layer, silicon cell, EVA and glass layers are considered as $4 \mu \mathrm{m}, 200 \mu \mathrm{m}$, $460 \mu \mathrm{m}$ and $3 \mathrm{~mm}$, respectively. Also, the width of interconnection ribbon is considered as $1 \mathrm{~mm}$. The thickness of the solder layer and interconnection materials (silver and copper) are changed to find geometrical effect of PV module interconnection on the CIT and the CGR parameters.

To have the equal electrical resistance of ribbons, for each copper thickness, the cross-section area of LCR interconnection is considered equal to the cross-section area of the relevant $\mathrm{CR}$ interconnection. For example, $250 \mu \mathrm{m}$ thick LCR interconnection is the relevant ribbon for $200 \mu \mathrm{m}$ thick CR interconnection.

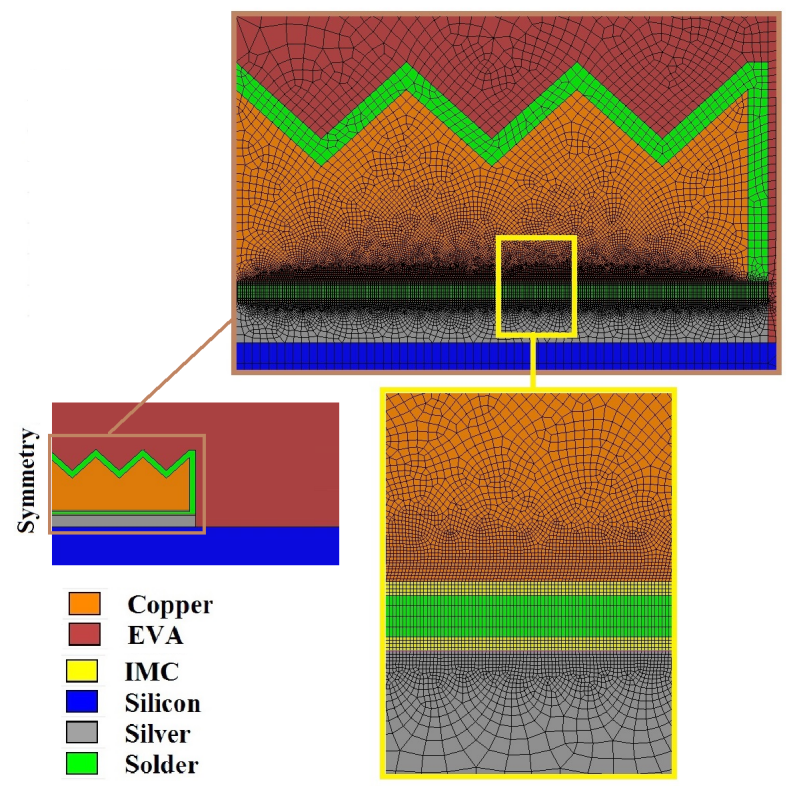

Figure 2 FE view of LCR interconnection (Symmetry constraints are applied)

\section{FEM RESULTS AND DISCUSSION}

Various solder, copper and silver thicknesses are considered to find the effect of geometrical parameters of LCR interconnection on the CIT and the CGR; and the results are compared to the results of the relevant CR interconnection found in the previous work ${ }^{[12]}$. The results of XFEM investigation of LCR interconnections showed that the location of crack initiation and the propagation direction are same as the CR interconnections, which the cracks are initiated at the edge of IMC layers interface with the copper ribbon and it is propagated in the shear direction due to low strength of the IMC layer.

\subsection{Effect of Solder and Copper Thickness Change}

Figure 3 shows the CIT in LCR interconnection and CR interconnection for different solder and copper 
thicknesses when the silver thickness is considered as $50 \mu \mathrm{m}$. The results indicate that for all copper thicknesses, there are similar trends of the CIT changes via solder thickness changes. Figure 3 shows that for LCR interconnection, the peak of CIT is when the solder thickness is $20 \mu \mathrm{m}$ and this offers the highest reliability since the crack is nucleated at higher temperatures.. Also, Figure 3 illustrates that for both LCR and CR interconnections, with increasing the copper thickness, there is a reduction in the CIT; this means that the thicker ribbons cause earlier crack initiation in the solder joint materials. This effect of copper thickness is also found when LCR interconnection is compared to the relevant CR interconnection. However, LCR interconnections are cracked at lower temperatures rather than $\mathrm{CR}$ interconnection due to using thicker copper layer.

Figure 4 shows the CGR in both LCR and CR interconnections for different copper and solder joint thickness. As it is seen in Figure 4, with increasing the thickness of the solder joint, the CGR increases fast and this causes larger cracks and more affects the strength of the joint connection of the PV module interconnection. Figure 4 also demonstrates that for narrow ribbons, LCR interconnection has less CGR rather than CR interconnection and this means that the structured design (LCR) suggests more reliability even when LCR has lower CIT. The graph also suggests that when the solder thickness is less than $30 \mu \mathrm{m}$, there is no any pronounced difference in the CGR values of LCR interconnection, but in LCR interconnection with the solder joints thicker than $30 \mu \mathrm{m}$, with decreasing the copper thickness, the CGR decreases. However, for CR interconnection, there is an opposite trend as the thicker CR interconnections have less CGR.

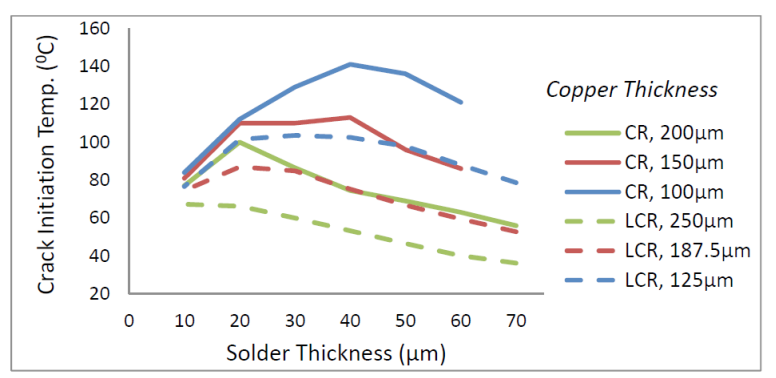

Figure 3 The crack initiation temperature (CIT) in LCR interconnection (this study) and in CR interconnection ${ }^{[12]}$ for different solder and copper thicknesses (note: the silver thickness is considered as 50 $\mu \mathrm{m}$ )

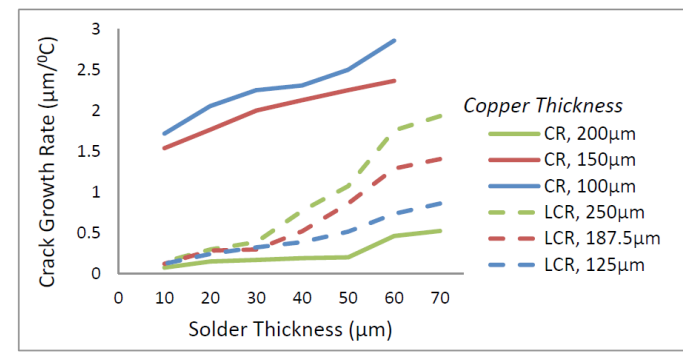

Figure 4 The crack growth rate (CGR) in LCR inter7connection (this study) and in CR interconnection ${ }^{[12]}$

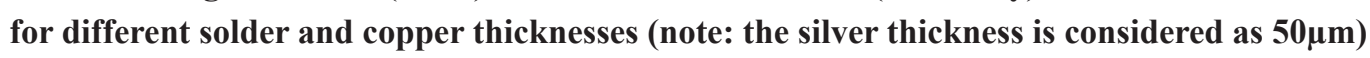

\subsection{Effect of Silver and Copper Thickness Change}

Figure 5 and Figure 6 show the CIT and the CGR in both LCR and CR interconnection, respectively, for different silver and copper thicknesses. The solder thickness is considered as $20 \mu \mathrm{m}$ as it is found as an optimum solder thickness to have the highest CIT and low CGR (see section 3.1).

Figure 5 shows that the peak of the CIT in LCR and CR interconnections is when the silver thicknesses are $40 \mu \mathrm{m}$ and $50 \mu \mathrm{m}$, respectively. It is found that the pick of the CIT in LCR interconnection $\left(106^{\circ} \mathrm{C}\right)$ is same as CR interconnection, but for thicker silver pads than $40 \mu \mathrm{m}$, the LCR interconnection experiences lower CITs. Figure 5 
also states that using the thicker interconnection ribbon results in a reduction of the CIT for both designs, as it is mentioned in section 3.1.

Figure 6 shows that the CGR in LCR interconnection with $125 \mu \mathrm{m}$ and $187.5 \mu \mathrm{m}$ copper thicknesses have experienced lower values compared to relevant CR interconnection $(100 \mu \mathrm{m}$ and $150 \mu \mathrm{m}$ thick coppers). However, for LCR interconnection with $250 \mu \mathrm{m}$ copper thickness, the CGR is higher than the CGR in relevant CR interconnection $(200 \mu \mathrm{m}$ thick copper). It is seen that when the silver thickness increases, the CGR decreases and this improves the reliability of the PV module interconnection. In addition, the graph suggests that for the silver pads with thickness lower than $40 \mu \mathrm{m}$, the thicker ribbons have lower CGR.

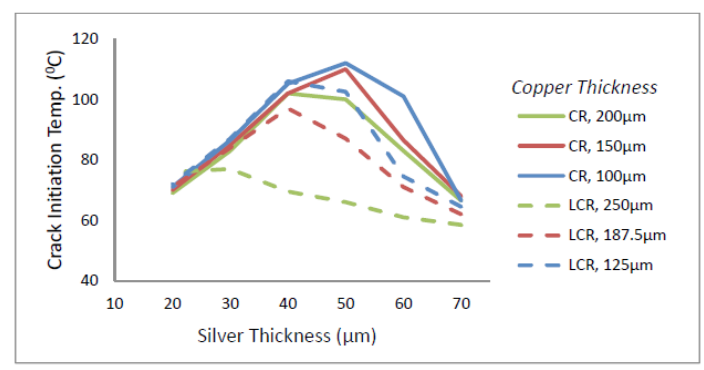

Figure 5 The crack initiation temperature (CIT) in LCR interconnection (this study) and in CR interconnection $^{[12]}$ for different silver and copper thicknesses (note: the solder thickness is considered as 20 $\mu \mathrm{m}$ )

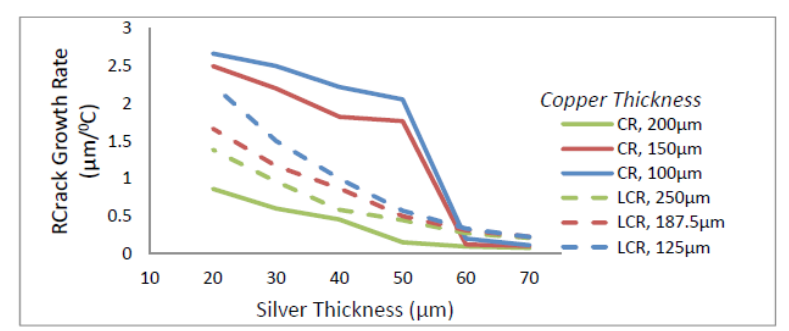

Figure 6 The crack growth rate (CGR) in LCR interconnection (this study) and in CR interconnection ${ }^{[12]}$ for different silver and copper thicknesses (note: the solder thickness is considered as $20 \mu \mathrm{m}$ )

Figure 7 shows the calculated crack length in LCR and CR interconnections at high manufacturing process temperature $\left(150^{\circ} \mathrm{C}\right)$ for interconnection ribbons with different copper and silver thickness (solder thickness is $20 \mu \mathrm{m}$ ). According to Figure 7, the crack lengths in LCR interconnection with copper thicknesses of $125 \mu \mathrm{m}$ and $187.5 \mu \mathrm{m}$ are less than the crack length in the relevant CR interconnections and only for the $250 \mu \mathrm{m}$ thick LCR interconnection, the crack length is larger than the crack length in the $200 \mu \mathrm{m}$ thick CR interconnection. Also, it is seen that for the silver pad thicker than $40 \mu \mathrm{m}$, the crack length in LCR interconnection is independent on the copper thickness. Hence, LCR interconnection with copper thicknesses of $125 \mu \mathrm{m}$ and $187.5 \mu \mathrm{m}$ (thin ribbons) can suggest more reliability for the PV module interconnection rather than the relevant $\mathrm{CR}$ interconnections.

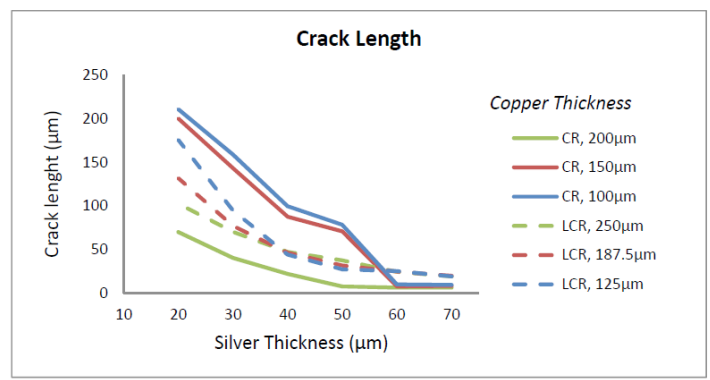

Figure 7 Crack length at $150^{\circ} \mathrm{C}$ in LCR and CR interconnection for different silver and copper thicknesses when the solder thickness is considered as $20 \mu \mathrm{m}$. 


\section{CONCLUSION}

This paper studies the crack initiation temperature (CIT) and the crack growth rate (CGR) in Light Capturing Ribbon (LCR) interconnection of the PV module at high temperatures of the manufacturing process. The results from Extended Finite Element Method (XFEM) in ABAQUS 2019 are found for the LCR interconnections and they are compared to the relevant results for the Conventional Ribbon (CR) interconnections.

The Cu thicknesses of LCR interconnection are considered as $125 \mu \mathrm{m}, 187.5 \mu \mathrm{m}$ and $250 \mu \mathrm{m}$ to have the same cross section area of the CR interconnection with the thicknesses of $100 \mu \mathrm{m}, 150 \mu \mathrm{m}$ and $200 \mu \mathrm{m}$, respectively. Different configurations including silver, copper and solder thickness are considered to study the effect of each parameter on the CIT and the CGR.

The results show that there is a same trend of the CIT and the CGR for both CR and LCR interconnections. For both designs, it is found that the location of the cracks is at the edge of the Intermetallic Compound (IMC) layers and the cracks propagates in shear direction. Compared to CR interconnection, LCR interconnections are cracked in the lower temperatures, but they experienced lower values of the CGR.

We found that the LCR interconnection experiences a peak of CIT when the solder and the silver pad thicknesses are $20 \mu \mathrm{m}$ and $40 \mu \mathrm{m}$, respectively, as for thicker silver pads, there is a fast reduction of the CIT. The results show that thicker copper ribbon has earlier crack initiation in the solder joint materials. It is also showed that for solder joints thicker than $20 \mu \mathrm{m}$, the CGR increases fast and makes larger crack which adversely affect the strength of the joint connection and the reliability of the PV module interconnection. However, with increasing the silver thickness, there is a high reduction in the CGR values.

The optimum solder, silver and copper thickness for LCR interconnection are recognized as $20 \mu \mathrm{m}, 40 \mu \mathrm{m}$ and 125-187.5 $\mu \mathrm{m}$, respectively, where this configuration experiences high CIT and low CGR and then crack length in the solder joint material is shorter than the crack length in the relevant $\mathrm{CR}$ interconnection.

Author Contributions: Alireza Eslami Majd undertook XFEM simulations and results and Nduka Nnamdi Ekere supervised the work.

Acknowledgments: The authors would like to acknowledge the support of the Faculty of Science and Engineering, University of Wolverhampton for providing the PGR Scholarships and Bursary Scheme for the corresponding author's Ph.D. studies.

Conflicts of Interest: The authors declare no conflicts of interest.

\section{REFERENCES:}

[1] Wiese S, Kraemer F, Betzl N, Wald D. Interconnection Technologies for Photovoltaic Modules - Analysis of technological and mechanical Problems. s.l., 11th. Int. Conf. on Thermal, Mechanical and Multiphysics Simulation and Experiments in Micro-Electronics and Micro-Systems, EuroSimE 2010, IEEE 2010.

[2] Pareek S, Chaturvedi N, Dahiya R. Optimal interconnections to address partial shading losses in solar photovoltaic arrays. Solar Energy. 2017; 155: 537-551.

[3] Ramabadran, R. \& Mathur, B. L., 2012. A Comprehensive Review and Analysis of Solar Photovoltaic Array Configurations under Partial Shaded Conditions. International Journal of Photoenergy.

[4] M. Sachs E, Serdy J, Gabor A, van Mierlo F. Light-Capturing Interconnect Wire for 2\% Module Power Gain. 24th European PVSEC, Hamburg, Germany. 2009.

[5] Schneider A, Rubin L, Rubin G. Combined effect of light harvesting strings, anti-reflective coating, thin glass, and high ultraviolet transmission encapsulant to reduce optical losses in solar modules. Progress in 
Photovoltaics. 2014; 22(Research and Applications):830-837.

[6] Braun S, Micard G, Hahn G. Solar cell improvement by using a multi busbar design as front electrode. 2012;227-233.

[7] Walter J, Tranitz M, Volk M, Ebert C, Eitne U. Multi-wire interconnection of busbar-free solar cells. Energy Procedia 55. 2014; 380-388.

[8] Eslami Majd A, Ekere N. N.. Numerical analysis on thermal crack initiation due to non-homogeneous solder coating on the round strip interconnection of photo-voltaic modules. Solar Energy. 2019; Volume 194; 649655.

[9] Chung I, Son H.Y., Oh H, Baek U-I, Yoon N, Lee W-J, Cho E-C., Moon I-S.. Light Capturing Film on Interconnect Ribbon for Current Gain of Crystalline Silicon PV modules. IEEE 39th Photovoltaic Specialists Conference (PVSC), Tampa, FL, USA. 2013.

[10] Ulbrich. Light-Capturing Ribbon. 2013. [Online] Available at: https:/www.pvribbon.com/?s $=$ Light-Capturing+Ribbon\&x $=0 \& y=0$

[11] Wohlgemuth J.H., Cunningham D.W., Nguyen A.M., Miller J. Long Term Reliability of PV Modules, Barcelona. 2005; 1942-1946.

[12] Eslami Majd A,Ekere, N.N.. Crack initiation and growth in PV module interconnection. Solar Energy. 2020; Volume 206: 499-507.

[13] ABAQUS Inc. ABAQUS User's and Theory Manuals. Version 6.17, Providence Rhode Island, RI, USA. 2017.

[14] Du Z.Z. eXtended Finite Element Method (XFEM) in Abaqus. 2009. [Online] Available at: http://www.simulia.com/download/rum11/UK/Advanced-XFEM-Analysis.pdf

[15] Schiavone A, Abeygunawardane G.A., Silberschmidt. Crack initiation and propagation in ductile specimens with notches: experimental and numerical study. Acta Mechanica. 2015; DOI: 10.1007/s00707-015-1425-0.

[16] Zhong W, Qin F, An T, Wang T. Mechanical Properties of Intermetallic Compounds in Solder Joints. 2010.

[17] Deng X, Sidhu R, Chawla N. Influence of reflow and thermal aging on the shear strength and fracture behavior of Sn-3.5Ag Solder/Cu joints. Metallurgical and Materials Transactions. 2005; A 36(1): 55-64.

[18] AZoM. Silver - Applications and Properties of Silver. 2001. [Online] Available at: https://www.azom.com/properties.aspx?ArticleID $=600$

[19] Jing X, Lee U.H., Xu C, Niu Z, Hao H, Bae J.Y, Won J, Zhang W. Effect of pre-CMP annealing on TSV pumping in thermal budget and reliability test. IEEE 22nd International Symposium on the Physical and Failure Analysis of Integrated Circuits, Hsinchu, Taiwan, 2015.

[20] Cambridge University Engineering Department. Materials Data Book. Cambridge University Engineering Department Data Books. 2003.

[21] Owen-Bellini M, Zhu J, R.Betts T, Gottschalg R, Thermo-Mechanical Stresses of Silicon Photovoltaic Modules, Bangor, United Kingdom. 2015.

[22] Tippabhotla S.K., Radchenko I, Song W.J.R., Illya G, Handara V, Kunz M, Tamura N, A.O.Tay A, S.Budiman A. From cells to laminate: probing and modeling residual stress evolution in thin silicon photovoltaic modules using synchrotron X-ray micro-diffraction experiments and finite element simulations. Progress in Photovoltaics. 2017; Research and Applications 25: 791-809.

[23] Taulaukian Y, Kirby R, Taylar R, Desai P. Thermal expansion Metallic Elements and Alloys-Thermophysical Properties of Matter. New York: Springer Science+Business Media, LLC. 1975; Volume 12.

[24] Jiang N, Clum J.A., Chromik R.R. , Cotts E.J.. Thermal Expansion of Several Sn-based Intermetallic Compounds. Scripta Materialia. 1997; Volume 37, Issue 12: 1851-1854.

[25] Li J, Karppinen J, Laurila T, Ka J. Reliability of Lead-Free Solder Interconnections in Thermal and Power Cycling Tests. IEEE Transactions on Components and Packaging Technologies. 2012; Volume 32, No 2.

[26] Siviour C.R., Walley S, Proud W, Field J. Mechanical properties of SnPb and lead-free solders at high rates of strain. Journal of Physics D: Applied Physics. 2005; 4131-4139. 